\title{
QUANTIFICATION OF GLACIER DEPLETION IN THE CENTRAL TIBETAN PLATEAU BY USING INTEGRATED SATELLITE REMOTE SENSING AND GRAVIMETRY
}

\author{
K.-H. Tseng ${ }^{a, b, *}$, K.T. Liu ${ }^{\text {c }}$, C.K. Shum ${ }^{\text {d }}$, Y. Jia ${ }^{d}$ K. Shang ${ }^{d}$, C. Dai ${ }^{d}$ \\ ${ }^{\text {a }}$ Center for Space and Remote Sensing Research, National Central University, No.300, Jhongda Rd., \\ Jhongli City, Taoyuan, Taiwan 32001 - khtseng@csrsr.ncu.edu.tw \\ ${ }^{\mathrm{b}}$ Institute of Hydrological and Oceanic Sciences, National Central University, Taoyuan, Taiwan \\ ${ }^{c}$ Dept. of Civil Engineering, National Central University, Taoyuan, Taiwan -103322086@cc.ncu.edu.tw \\ ${ }^{\mathrm{d}}$ Division of Geodetic Science, School of Earth Sciences, the Ohio State University, Columbus, Ohio, \\ USA, 43210 - (ckshum, jia.102, shang.34, dai.56)@osu.edu
}

WG VIII/4 - Water Resources

KEY WORDS: Landsat, GRACE, Altimetry, Modified Normalized Difference Water Index (MNDWI)

\begin{abstract}
:
Glaciers over the Tibetan Plateau have experienced accelerated depletion in the last few decades due primarily to the global warming. The freshwater drained into brackish lakes is also observed by optical remote sensing and altimetry satellites. However, the actual water storage change is difficult to be quantified since the altimetry or remote sensing only provide data in limited dimensions. The altimetry data give an elevation change of surface while the remote sensing images provide an extent variation in horizontal plane. Hence a data set used to describe the volume change is needed to measure the exact mass transition in a time span. In this study, we utilize GRACE gravimetry mission to quantify the total column mass change in the central Tibetan Plateau, especially focused on the lakes near Tanggula Mountains. By removing these factors, the freshwater storage change of glacier system at study area can be potentially isolated.
\end{abstract}

\section{INTRODUCTION}

\subsection{Tibetan Plateau}

The Tibetan Plateau (TP) located in western China covers an area of 1.22 million $\mathrm{km}^{2}$, including more than 1000 alpine lakes with a total lake area $>40,000 \mathrm{~km}^{2}$. It also hosts approximate 36,000 glaciers across the region. The east and south edge of TP serves as the origin of several major river systems in Asia. There are numerous studies focused on TP, covering geophysics and climatology because of its geographical formation and responses to the climate change.

The glaciers in TP apparently suffered from an accelerated loss primarily due to the global warming in the last few decades. From remote sensing and in-situ record, the rising rate of temperature over the entire TP is estimated at about $0.03^{\circ} \mathrm{C}$ per year (Liu et al., 2000; Xu et al., 2009; Tseng et al., 2011) during the past 2-3 decades. This warming procedure has caused the growing water storage in many glacier-fed lakes. Therefore, monitor of lake changes provides an opportunity to study the amount of melting ice from thinning glaciers and due to changing patterns of precipitation. However, most of the studies (Zhang et al., 2013a) conducted so far either focused on lake extent change, or short-term water level change using limited sensors, and resulted in incomplete observation of hydrological changes (Tseng et al., submitted manuscript, 2016). The spatial/temporal limitations have made the exact quantification of water storage changes difficult.

\subsection{Study area}

There is a cluster of large lakes located near southern TP, e.g., Siling CO, Nam Co, and Yamzho Yumco. Several others are located near the central, adjacent to Tanggula Mountain ranges. Tanggula Mountains served as geographical boundary between the continental climate and the summer Indian monsoon over the plateau (Zhang et al., 2013b). The tallest peak, Gêladaindong Mountain is also the headwaters of Yangtze River. However, due to the climate change, temperature over the plateau manifests an increasing trend at about $0.016^{\circ} \mathrm{C} \mathrm{yr}^{-1}$ (Zhang et al., 2011). Most glaciers in Tanggula Mountains started to retreat in the last 50 years. The previous study showed that general retreat rate in glaciers near Gêladaindong is about one square kilometer per year (Zhang et al., 2008). Several adjacent lakes had been observed significant increasing in water volume. Therefore, it is quite a critical issue to accurately monitor and quantify glacier depletion and lake level rise in this area. Hence, we proposed to integrate multiple spaceborne measurements to study the long-term lake volume changes, including satellite radar altimetry, laser altimetry, optical remote sensing, and gravimetry approaches.

The twin lake named Chibuzhang Co (Fig., 1, right) and Dorsoidong Co (Fig. 1, left) is located in the central TP. Chibuzhang Co has the water sources coming from glaciers surrounding Gêladaindong peak within Tanggula Mountain ranges. Dorsoidong Co is a bit smaller than Chibuzhang (Song et al., 2015), where the water source is mainly from the Purog Kangri Mountain. Each of them was observed to be fluctuating independently in earlier years and became interlinked in the mid-2000 (Song et al., 2015). In this study, we focused on this major twin lake with a combined surface area greater than 1000 $\mathrm{km}^{2}$, which is large enough to represent major mass contribution in GRACE signal. 


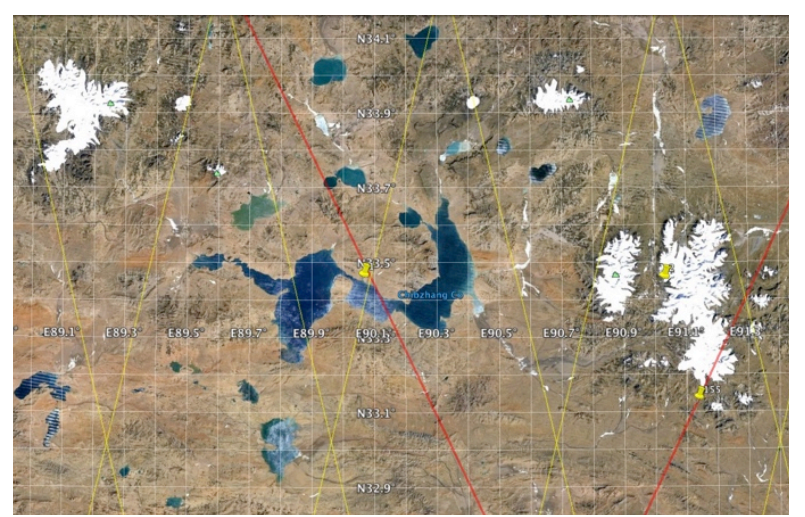

Figure 1. Geographic map of Chibuzhang Co and Dorsoidong Co. Red and yellow lines indicate groundtracks of Jason-2 and Envisat altimeters, respectively. This image is modified from Google Earth imagery.

\subsection{Satellite altimetry}

Satellite altimetry is a technology to monitor water surface heights from space. It generates radar (laser) pulses toward the Earth's surface and calculates time elapse until those signals are reflected from the nadir footprint and received by the onboard sensor. By measuring the two-way travel time of the pulse, the altimeter calculates the distance between satellite and reflecting facets. By knowing the position of altimetry satellite, the surface height can thus be derived. In this study, we used radar altimetry data obtained by Envisat and Jason-2, and laser altimetry data from ICESat.

\subsection{Optical satellite images}

Satellite optical imagery has been widely used in different applications, such as change detection, policy decisions, disaster prevention, and pollution monitoring. Landsat series is the most commonly used database for the mid-to-high resolution purposes. In this study, we used Landsat-5/-7/-8 to extract water area by using multispectral analysis. The Landsat series has medium spatial resolution (L-5/7: 30m, L-8: $15 \mathrm{~m}$ ) and multiple bands (L-5: 7 bands, L-7: 8 bands, L-8: 11 bands). The revisit period is 16 days. Most importantly, all the images in GeoTiff format were currently available in the U.S Geological Survey (USGS) EarthExplorer website (http://earthexplorer.usgs.gov) at no cost.

\subsection{Satellite gravimetry}

GRACE is a joint satellite mission between NASA in the U.S. and GFZ in Germany that provides exclusive information about large-scale mass transitions. It was lunched on March 7, 2002. GRACE is composed by two identical satellites about 220 $\mathrm{km}$ away from each other. The $\mathrm{K} / \mathrm{Ka}$-band microwave ranging (KBR) system, GPS receivers, and other onboard instruments are used to determine the orbit perturbation, mainly due to gravity anomaly. The gravity field can be derived from the distance change between the two satellite detected by the KBR system. However, the observation has a coarse resolution of about $330 \mathrm{~km}$, corresponding to spherical harmonics expansion complete to degree 60 , thus makes most lake studies difficult.

\section{DATA AND PROCESSING METHOD}

\subsection{Envisat, Jason-2, and ICESat}

Envisat is a European Space Agency mission launched in 2002. Following its predecessor ERS-1/-2, at a 35-day repeat period and about $80 \mathrm{~km}$ split of parallel groundtrack interval at the Equator. We used its $18 \mathrm{~Hz} \mathrm{Ku} / \mathrm{S}$ bands measurements retracked by ICE retracking algorithm, stored in the geophysical data record (GDR). We utilized ICE-1 retracking algorithm provided by CNES Archiving, Validation, and Interpretation of Satellite Oceanographic data (AVISO) with a time span covering regular operation mode, 2002-2012. ICE-1/ICE-2 algorithms developed for analyzing specular shape of waveform over ice sheet are applicable for lake observations with similar waveform patterns (Frappart et al., 2006; Lee et al., 2011).

The Ocean Surface Topography Mission (OSTM)/Jason-2 launched in 2008 is a follow-on mission of two successful predecessors, TOPEX/Poseidon, and Jason-1. It works in a nonsun-synchronous orbit with approximate 10-day revisit period to better solve short-term ocean surface changes. It carries a dualfrequency altimeter working in $\mathrm{Ku}$ and $\mathrm{C}$ bands. We utilized GDR version T (JA2_GPS_2PTP) provided by AVISO with the time span covering 2008 to 2012. Similar ICE retracking algorithm was used to extract water surface height at pass \#242 specified in Fig. 1. For both Envisat/Jason-2 altimeters, we first created a water mask $\sim 1 \mathrm{~km}$ away from the shoreline to prevent potential land contamination. A backscattering coefficient threshold at $15 \mathrm{~dB}$, indicating returned signal from a smoother surface in radar perspective, was selected to collect water measurements.

Laser altimetry data is obtained by Ice, Cloud, and land Elevation Satellite (ICESat) from 2003 to 2009. Principally similar to radar altimetry, it calculates the timing between transmissions of laser photons. By applying the photon counting technique (Abshire et al., 2005) for surface detection, the elevation of nadir surface is estimated. However, due to a pump diode failure soon after launch, ICESat switched into campaigned mode was switched to alternatively extend the mission life. It only worked in a 33-day to 56-day campaigns mostly in February-March/May-June/October-November during 2003-2009. The measurement at timing of season transitions is still valid to study gradual changes in the cryosphere and other phenology with interannual cycle.

\subsection{Landsat series}

Landsat-5 covered from 1984 to 2013. It carried the Thematic Mapper (TM) operated in 7 bands ranging between $450 \mathrm{~nm}$ and $2350 \mathrm{~nm}$. In 1999, Landsat-7 was launched with the Enhanced Thematic Mapper Plus (ETM+) similar to TM except for an extra panchromatic band at $15 \mathrm{~m}$ resolution. Finally, Landsat- 8 was launched lately in 2013 with an onboard Operational Land Imager (OLI), sensing wavelengths between $430 \mathrm{~nm}$ and $2290 \mathrm{~nm}$. While combined with the Thermal Infrared Sensor (TIRS), the spectral coverage is up to 12510 $\mathrm{nm}$.

The combined time span of a suite of Landsat imageries allows us to observe the movement of this twin lake. For spectral resolution, Landsat imagery covering from visible light to infrared band is sufficient to detect water existence. The WRS path/row at this twin lake is frame $139 / 37$. In this study, all the available raw images were first gathered and then appropriate images with less cloud cover along shoreline were selected to extract water surface information.

For all collected images, the radiometric information stored as Digital Numbers (DN) in each pixel was first converted into Top-of-Atmosphere reflectance (ToA). The conversion addresses effects caused by varying sunlight angle and distance, identical to the method introduced in Chander et al., 2009. For Landsat- 8 images, the conversion follows standard procedure given in USGS website (USGS, 2015). 
Then, we used the images to calculate MNDWI and recognized water body in the images. By analyzing the temporal change of water surface area, we can infer the seasonal and long-term lake change by using remote sensing imagery.

$$
\text { MNDWI }=\frac{G-M I R}{G+M I R}
$$

Where $\mathrm{G}$ is the green band, MIR is the mid-infrared band.

Since the bandwidth and band center has a bit shift across Landsat optical sensors, a selection of band and customized threshold setup was used. Once the MNDWI of each image is composed, a thresholding procedure was used to divide each pixel into water or non-water group. Finally, we obtained the elevation data along shoreline from DEM based on the TIAS system proposed in Tseng et al. (2015).

\subsection{GRACE data}

GRACE is a suitable approach to obtain both static and temporal gravity fields. The static part can be defined as the long-term average of the total mass measured by GRACE. Once the static gravity field has been determined, we can take the long-term mean off, and then assume some factors below the crust remains unchanged and all the atmospheric loading can be well eliminated. If so, the mass change left in the gravity anomaly is surface water, soil moisture and groundwater mass change and other mass redistribution on the Earth's surface. Here, we used GRACE solution generated by the GRACE plotter service, provided by CNES (http://www.thegraceplotter.com/) for a qualitative comparison.

\section{RESULT}

Temporal water level variation of Chibuzhang Co and Dorsoidong Co analyzed separately by TIAS is shown in Fig. 2. In this figure, we observe that these two lakes varied independently before 2005, with a clear separation in height and the difference became unclear in 2007. Similar to previous study, the Dorsoidong Co experienced a sharp increase in water level in early 2000 while the Chibuzhang Co remained almost stable. The two lakes first became interlinked in late 2004 .

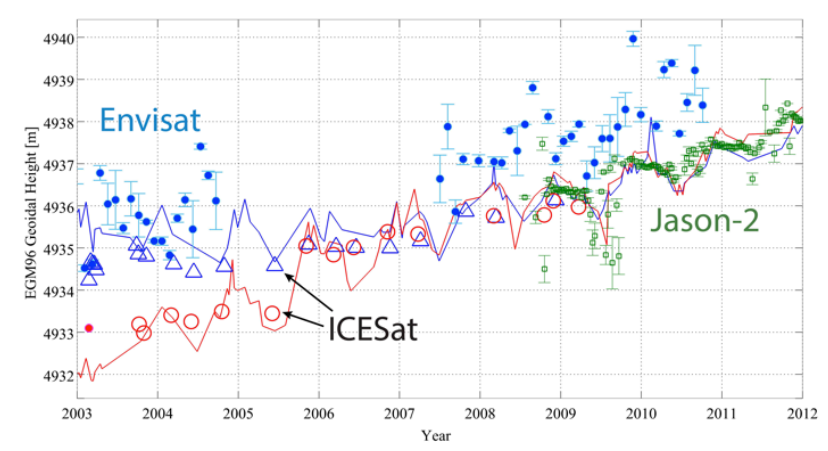

Figure 3. Lake level change measured by TIAS (blue and red solid lines), Envisat, Jason-2 and ICESat.

By comparing the altimetry result with GRACE data in a broader scale, we notice that the increasing trend of mass change meshes well with each other. In Fig. 4, the GRACE time series in equivalent water height $(\mathrm{EWH})$ has a similar increasing tendency during 2003-2012. However, it is known that GRACE data, covering approximately $300 \mathrm{~km}$ grid, is a combination of surface, subsurface, and even tectonic signals. The information of other mass contribution, such as rainfall input, is necessary for the quantification of glacier contribution from the lake signal. This issue remains a major challenge at current stage.

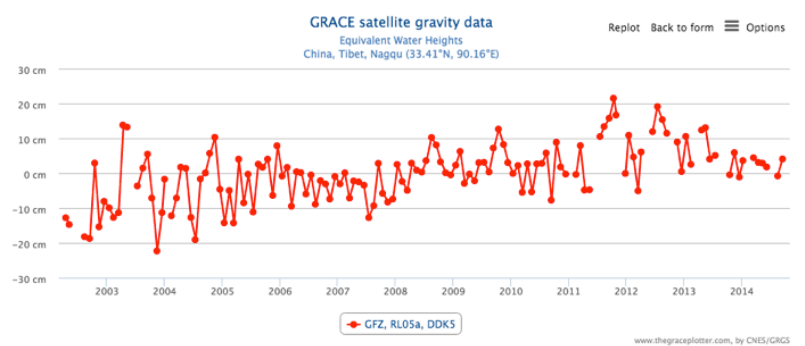

Figure 4. Mass change measured by GRACE and presented in EWH. The time series is generated by the GRACE plotter service provided by CNES. The data used here is monthly solution released by GFZ.

\section{CONCLUSION}

Water level at a twin lake near central TP has been observed by different spaceborne sensors. An increasing trend of mass balance is observed in either water level/volume change or gravity signals. However, due to the limitation in space resolution, it is difficult to separate mass contribution from various aspects, such as precipitation and groundwater. Auxiliary data such as hydrological models would be helpful on solving this problem towards quantify the mass transition from glacier to the adjacent lakes.

\section{REFERENCES}

Abshire, J. B., Sun, X., Riris, H., Sirota, J. M., McGarry, J. F., Palm, S., ... \& Liiva, P., 2005. Geoscience laser altimeter system (GLAS) on the ICESat mission: on-orbit measurement performance. Geophysical Research Letters, 32(21).

Chander, G., Markham, B. L., \& Helder, D. L., 2009. Summary of current radiometric calibration coefficients for Landsat MSS, TM, ETM+, and EO-1 ALI sensors. Remote sensing of environment, 113(5), 893-903.

Duan, X. J., Guo, J. Y., Shum, C. K., \& Van Der Wal, W., 2009. On the postprocessing removal of correlated errors in GRACE temporal gravity field solutions. Journal of Geodesy, 83(11), 1095-1106.

Frappart, F., Calmant, S., Cauhopé, M., Seyler, F., \& Cazenave, A., 2006. Preliminary results of ENVISAT RA-2-derived water levels validation over the Amazon basin. Remote sensing of Environment, 100(2), 252-264.

Guo, J. Y., Duan, X. J., \& Shum, C. K., 2010. Non-isotropic Gaussian smoothing and leakage reduction for determining mass changes over land and ocean using GRACE data. Geophysical Journal International, 181(1), 290-302.

Lee, H., Shum, C. K., Tseng, K. H., \& Guo, J. Y. \& CY Kuo., 2011. Present-day lake level variation from ENVISAT Altimetry over the northeastern Qinghai-Tibetan Plateau: Links with precipitation and temperature. J. Terrestrial Atmos. Ocean Sci, 22, 169-175.

Liu, X. \& Chen, B., 2000. Climatic warming in the Tibetan Plateau during recent decades. Int. J. Climatol., 20, 1729-1742. 
Song, C., \& Sheng, Y., 2015. Contrasting evolution patterns between glacier-fed and non-glacier-fed lakes in the Tanggula Mountains and climate cause analysis. Climatic Change, 1-15.

Tseng, K. H., Shum, C. K., Lee, H., Duan, J. B., Kuo, C. Y., Song, S. L., \& Zhu, W. Y., 2011. Satellite observed environmental changes over the Qinghai-Tibetan Plateau. Terrestrial, Atmospheric and Oceanic Sciences, 22(2), 229-239.

Tseng, K. H., Shum, C. K., Kim, J. W., Wang, X., Zhu, K., \& Cheng, X., 2015. Integrating Landsat Imageries and Digital Elevation Models to Infer Water Level Change in Hoover Dam. IEEE Journal of Selected Topics in Applied Earth Observations and Remote Sensing, vol.PP, no.99, pp.1-14

Tseng, K.-H., Chang, C.P., Shum, C.K., Kuo, C.Y., Liu, K.T., Shang, K., Jia, Y., \& Sun, J. Quantifying Freshwater Mass Balance in Central Tibetan Plateau by Integrating Satellite Remote Sensing, Altimetry and Gravimetry. Remote Sensing, submitted.

USGS, Using the USGS Landsat 8 Product, http://landsat.usgs.gov/Landsat8_Using_Product.php.

Xu, B., Cao, J., Hansen, J., Yao, T., Joswia, D. R., Wang, N., Wu, G., Wang, M. Zhao, H., Yang, W., Liu, X., \&He, J., 2009. Black soot and the survival of Tibetan glaciers. Proc. Natl. Acad. Sci. USA, 106, 22114-22118, L20815, doi: 10.1029/2008GL035867.

Zhang, G., T. Yao, H. Xie, S. Kang, and Y. Lei., 2013a. Increased mass over the Tibetan Plateau: From lakes or glaciers? Geophys. Res. Lett., 40, 2125-2130, doi:10.1002/grl.50462.

Zhang, J., Braaten, D. A., Li, X., \& Tao, F., 2013b. An inventory of glacier changes between 1973 and 2011 for the Geladandong Mountain area, China.

Zhang, Y., Yao, T., \& Ma, Y., 2011. Climatic changes have led to significant expansion of lakes in Xizang (Tibet) since 1995. Sciences in Cold and Arid Regions, 3(6), 0463-0467.

Zhang, Y., Liu, S.Y., Xu, J.L., Shangguan, D.H., 2008. Glacier change and glacier runoff variation in the Tuotuo River basin, the source region of Yangtze River in western China. Environmental Geology 56, 59-68. 